\title{
Practice and Exploration on the Innovation of Talent Training Model of the Art and Design Professionals
}

\begin{abstract}
Zhaocheng Wang*
School of Economics, Sichuan University, Chengdu, Sichuan, China

*Corresponding author

ABSTRACT

The innovation-driven development strategy implemented in our country needs the support of innovative human intelligence resources, and it is the sacred duty and mission entrusted to our educators. On the basis of the research and analysis of the present situation of the art design professional education, combining with the practice and exploration of the teaching reform, the teaching mode of the innovative personnel training and how to create an innovative education atmosphere environment are studied. Taking the case-driven analysis to impart knowledge teaching mode as the main line, focusing on the practical teaching to stimulate students' creative potential, constantly updating and perfecting the knowledge system structure of talent training education, which plays a positive role in promoting the implementation of innovative talent training education project.
\end{abstract}

Keywords: Educational and talent training model, Practice driving development, Innovation talent education,

Case-driven teaching, Heuristic teaching

\section{INTRODUCTION}

Innovation is the most precious spiritual wealth of mankind. It is the soul of national progress and the inexhaustible motive force of the state. If a country does not have innovative thinking and innovation capacity, it is difficult to adapt to the rapid development and social progress of the new era ${ }^{[1]}$. Among the five major development concepts put forward by the 19th CPC National Congress, the most distinctive national endowment of the Chinese nation "innovative development", is ranked first in order to show our party's determination and confidence in innovative development to realize the great national rejuvenation of Chinese Dream, and to make major plans to implement the strategy of innovation-driven development. It is proposed that we should adhere to the road of independent innovation with Chinese characteristics and plan and promote innovation from a global perspective ${ }^{[2]}$.

We must improve the ability of independent innovation for building an innovative country. This is the core idea that drives the national development strategy, and it is also a sacred duty and glorious mission to give our higher education workers to implement innovative education development. Combined with the practice and investigation of cultivating and educating technical talents in art engineering in comprehensive colleges and universities, I think that innovating the model and method of training education has become an important problem for continuous exploration, thinking and urgent need.

The innovation is the essence of the quality and ability of the art design. The cultivation of the innovative consciousness and the innovation ability should be throughout the education. Art design contains strong professional basic knowledge, techniques and skills, but also needs to keep pace with the times closely with social practice. In the whole process of education, teaching and practice, we should pay more attention to effectively integrating the leading thought of cultivating innovative talents into every link of daily teaching. How to implement the innovation education is to start with the cultivation of the innovative spirit, to improve the innovation ability as the core, to drive the self-building and harmonious development of the whole quality of the students. For the establishment of innovative consciousness and the cultivation of innovative spirit is the key to higher education, innovative education and teaching environment, mode and method are the core of cultivating contemporary college students' innovative ability ${ }^{[3]}$. Because the urgent need of innovative talents in today's society lies not only in how much knowledge information they have in the whole innovative knowledge system, but also in having a solid professional basic knowledge, strong innovative thinking, innovative spirit and innovative ability to analyze and solve problems. In the basis of studying and analyzing the present situation of the cultivation of art and design professionals in colleges and universities, this paper makes a beneficial practice and exploration on the ways and means of cultivating innovative talents. 


\section{AN ANALYSIS OF THE CURRENT SITUATION OF THE EDUCATION OF ART DESIGN}

The specialty of art and design has the characteristics of strong practicality and professionalism. The investigation and analysis of the demand for talents in today's society shows that the social demand for its professionals is large, and it also involves a wide range of industries and application fields. The requirements for professional literacy and ability are relatively high, especially for graduates with a solid professional foundation and strong ability to analyze and solve problems independently. The demand of compound talents is greater and more urgent, and it can be said that those who have certain innovative ideas and abilities are more difficult to find and are in demand.

At present, due to many reasons, the mode of talent training and education is not in line with the pace of rapid development of the times, and is out of touch with the requirements of the professional ability standards urgently needed by social talents. The main reason is that, with the rapid development of the society and the progress of science and technology, the cultivation mode of the art talents is mainly based on the traditional pure art theory education, and the corresponding training environment of the personnel training is not small, and the teaching method is also single; It is mainly based on the classroom imparting theoretical knowledge and offering too many courses, and there are few practical or practical teaching links and lack of measures, especially the infiltration of students' innovative thinking and the cultivation of innovative consciousness are not enough, which is not conducive to students' in-depth understanding of art theory thought, and neglects the ability demand of art design practice to cultivate students' work creation, re-creation and innovation development.

Nowadays, with the development of the new generation of information science and technology and the deepening of the information teaching equipment in the classroom, with the assistance of the information teaching system, the way and means of classroom teaching have undergone profound changes. Multimedia courseware, video display of design works and 3D virtualization design process teaching have been widely used. Through the way of the Internet and the video image of the wireless network, the foreign advanced design idea and the propaganda of the design product are introduced to the students, so that they can more deeply understand the artistic theory thought, and also open the field of view of the design of the work, and cultivate the consciousness and the ability of the creative thinking. However, in the whole process of education and training, there are still some new problems to be solved.

The design of teaching curriculum is not closely connected with the professional knowledge needed by talents in real society, and the teaching practice and content are divorced from the urgent requirements of talent knowledge structure and ability. The students have a wide range of knowledge, and the thinking of the mind is rich, but the base of the professional foundation is insufficient, and the actual combat ability to solve the actual problems is not good. So that the content and the task of the teaching practice link are difficult to be finished better. It can be said that they are "in that head"; with "The hand is too slow to do it.", even if they are made, there is often a lack of creative thinking ability, the design thought is impetuous, the work is hard to move, or serious plagiarism.

It is urgent to solve the social contradiction of the serious imbalance between the supply and demand of the art talents. Which must closely follow the development and progress of the time and technology of the times, reform the traditional education and culture model and the knowledge structure, and adapt to the demand of the talents of the art design in the social development. With the increasing number of students increasing year by year, it cannot be said that the students trained by the school are not the people that the society wants, but only the fewer people who meet the needs of the society.

There are few teachers with "double-teacher type" qualification or experience as teaching task. With the development of knowledge structure and ability of the times, the teachers also need to advance with the times. Teachers are the key to the implementation of innovative education. If teachers' ideas and professional ability are not changed, it is impossible to cultivate college students with innovative consciousness and meet the needs of society. Therefore, it is urgent to strengthen the construction of teachers, reconstruct their knowledge structure, improve the level of professional technology and comprehensive ability, in order to adapt to the ecological environment of innovative and skilled personnel training and education, and meet the requirements of social development.

\section{INNOVATING THE TEACHING MODE OF THE TALENTS AND THE CREATION OF AN INNOVATIVE EDUCATION ENVIRONMENT}

1. Reforming the Teaching method of the Classroom and utilizing the Teaching Mode of the Case-driven Analysis

(1) The multi-use heuristic teaching method is concerned with the design of new thinking of the students. The teacher should change the traditional teaching mode, and the teacher should change from the informer of teaching knowledge to the leader who inspired the education. Encourage students to make bold and innovative thinking and change the mode of the judge of an answer. By combining the case analysis and driving, the students are inspired to answer the questions such as "Why?", "How to do it", "What's the matter" and so on, and drive the students to create different new cases according to the design thoughts and principles of the case, so that the students can reconstruct and update the knowledge to A higher level of understanding of knowledge. The main results are as follows: students are required to carry out 
disunified analysis and design different results; then, under the guidance of teachers, they are asked to make a comparative analysis of the advantages and disadvantages of their own independent design cases, so as to provide a good environment atmosphere for cultivating students' innovative consciousness, bold design and self-demonstration [4].

2. For example, in the process of teaching combined with cases, students are inspired to observe and analyze from more visual angles, and then guide them how to carry out innovative design. In the case of teaching, students are encouraged to use different materials to produce different, similar or better works. Then, it is more beneficial for students to learn and use spontaneous innovation, radiate their passion of innovation consciousness and enhance their confidence and ability of innovative design, by commenting or instructing the works created by students who have the same knowledge points but different effects from the classroom examples.

(2) It is appropriate to use the subject cooperation and inter-teaching method to promote the interactive communication between students and students, students and teachers. The teacher can select a high degree of correlation with the content of the teaching knowledge, have a representative subject, and encourage the students to participate actively in order to exercise the creative ability of the bold and innovative thinking design. Through the interaction and cooperation of the students and the teachers, a project is completed, so that the students can be creatively integrated into the creative group in the participation, not only can the students' innovation ability and cooperation ability be exercised, it also provides a sense of confidence and a sense of achievement through collaboration with the teacher and thinking.

(3) It is effective to adopt the open practice teaching of the school-enterprise cooperation, and stimulate the students' creative potential to adapt to the future work development requirements. Nowadays, the creation and design of art products has been widely used in many fields of society. Using 3D, virtual reality, animation and multimedia and other advanced technologies, the creation and design of all kinds of products or works are colorful and emerge in endlessly. In order to meet the needs of social development, educators must provide a platform for college students to cooperate with enterprises to carry out open education, and combine the professional theoretical knowledge learned with the practical application of society. Through open practical education, students can not only broaden their horizons to exercise their practical ability, but also give full play to the role of students as a productive force resource, and feed back to serve the social and economic development. Making students come into contact with the design idea, work steps and business environment as soon as possible, as well as communication and technical exchange with social related fields, will have an important impact on students' pioneering and enterprising vision, exercise their actual combat ability and cooperative communication ability, and improve their own comprehensive quality, all of which will have an important impact and benefit for life.
3. To make a long story short, in the process of implementing innovative education, instructors will play an extremely important and irreplaceable role as a bridge and link. As an educator, it is necessary to encourage students to give full play to their autonomy, creativity, the vitality of innovative thinking and the initiative of their own active participation in playing the leading role of initiator and guide in students' learning. I think enlightening, guiding and encouraging students to carry out innovative art and design education, and carry out beneficial cooperation with students in industry, education and research. What we have gained is not only experience and lessons, but also the feelings of teachers and students, from mutual knowledge to acquaintance, from respect to respect, and to the happiness and glory of teaching and educating people.

1. Constantly renew the knowledge structure of Professional Design and perfect the Education and Teaching system of Talent training

The specialty of art and design has the characteristics of strong practicality and comprehensiveness, and the works created are especially prominent in serving the society with commodity type. With the development of the ability of science and technology to provide technical support for product design and diversification, it is imperative to change the traditional thinking mode of art education because of the continuous improvement of the level of artistic aesthetics. Because the current teaching mode of art education attaches too much importance to the basic theory of art, new design ideas, theories and methods, and other professional knowledge, and lack of timely updating to the implementation of the syllabus curriculum plan. Therefore, according to their own professional advantages, appropriate opening of public courses and expansion of elective courses, students can choose a certain amount of public or elective courses, such as Art Economics, Consumer Psychology, VR design, 3D MAX, 3D Maya, Java programming, CSS web design and other courses [5] to meet the needs of students for professional skills. In order to overcome the phenomenon of emphasizing theory over practice, we should appropriately increase the credits and hours of design practice class, and strengthen the cultivation of students' practical ability.

2. Enlighten the teaching and the ability training double drive, create the student specialized ability promotion big environment.

Changing the teaching method of imparting knowledge in classroom and case-driven analysis teaching innovation mode is only the first step in teaching knowledge to enlighten and educate students, and constantly updating the knowledge structure of professional design and perfecting the education and teaching system of talent training is only a further help to perfect students' professional structure knowledge in the face of the progress of the times and the development of disciplines. The practice of artistic creation is the key link to cultivate students' innovative consciousness and improve their innovative ability, and it is also the ultimate goal of carrying out innovative talent education. 
However, if there is no environment for the cultivation and education of innovative talents, it is difficult to say that a large number of innovative talents can be trained. American psychologist Solitelford believes that creativity is cultivated by the "social atmosphere" in which the subject lives, that is, the creative environment. To create a social environment that advocates innovation and to cultivate a school environment with innovative ability, in addition to offering different innovative practical courses at different stages of teaching, introducing new design elements and styles, introducing the best design works to accumulate resources for students' creation, arousing students' creative inspiration and improving aesthetic literacy, there are also many different organizational forms. Students are encouraged to participate in art creation competitions and hold exhibitions of design works, so that they can get practical training in innovative thinking and creative ability, and absorb modern art nourishment and advanced design experience in the exhibition. At the same time, we should constantly increase the investment of practical teaching environment, create an open and good professional ecological environment for the cultivation of innovative talents and stimulate students' independent innovation and creative passion.

\section{CONCLUSION}

Some ideas and beneficial explorations putted forward by practice can be used for reference. Art design is the process in which people give full play to their own artistic intelligence and potential to realize creation, so that college students can learn how to make use of the knowledge, skills and innovative thinking ability they have learned to create better art and design works. Which is the focus of cultivating innovative talents, and it is also the driving force to carry out the training and education of innovative talents in the face of the new needs of social talents with the development of society and the progress of science and technology. In order to meet the urgent need of innovative talents in today's society, it is a duty to cultivate students' innovative thinking consciousness and ability to practice innovation. It is still necessary to carry out in-depth research and active exploration.

\section{REFERENCES}

[1] Qian Xuesen. Carry out the research of thinking science. Speech at the first National Symposium on thinking Science; 1984.

[2] The importance of innovative education and the improvement of innovation ability. https://wenku.baidu.com/view/259b7cbdb84ae45c3a35 8c5a.html.2018

[3] Wang zhaocheng. Investigation for Countermeasures and Ways of Cultivating Innovative Students of Art Design in University. The 2015
International Conference on Social Science and Higher Education (ICSSHE 2015). Sanya, China. Dec.26-27, 2015.

[4] Wang Zhaocheng. 3D Art Design hand-in-hand training course, Tsinghua University Press (ISBN 978-7- 302- 24615 -2). 2011.6

[5] Wang Zhaocheng. Maya 3D Animation Design case-driven tutorial. Published by Zhengzhou University (ISBN 978-7-5645-2546-0). 2017.10. 